\title{
Magnesium hydrogen breath test using end expiratory sampling to assess achlorhydria in pernicious anaemia patients
}

P Humbert, P López de Soria, F Fernández-Bañares, J Juncá, J Boix, R Planas, J C Quer, E Domenech, M A Gassull

\begin{abstract}
A modified magnesium hydrogen breath test, using end expiratory breath sampling, is described to investigate achlorhydria. The efficacy of this test in the diagnostic investigation of pernicious anaemia was compared with that of serum pepsinogen I. Twenty one patients with pernicious anaemia - that is, patients with achlorhydria - and 22 with healed duodenal ulcer and normal chlorhydria were studied. Magnesium hydrogen breath test, serum pepsinogen I, serum gastrin, and standard gastric acid secretory tests were performed in all subjects. The mean (SEM) hydrogen peak value was lower in patients with pernicious anaemia than in the duodenal ulcer group $(21.7(1 \cdot 9) v 71.3(5 \cdot 2) \mathrm{ppm} ; \mathrm{p}=0.00005)$. The hydrogen peak value had a $95 \cdot 2 \%$ sensitivity and a $100 \%$ specificity to detect pentagastrin resistant achlorhydria. Mean serum pepsinogen I concentrations were also significantly lower in patients with pernicious anaemia than in the duodenal ulcer group $(10.7(2.7) v 123.6$ (11.8) $\mu g / 1 p=0 \cdot 00005)$. Sensitivity and specificity to detect pernicious anaemia were both $100 \%$ for pepsinogen I. It is concluded that this modified magnesium hydrogen breath test is a simple, noninvasive, cost effective, and accurate method to assess achlorhydria and may be useful in the diagnostic investigation of patients with suspected pernicious anaemia.
\end{abstract}

(Gut 1994; 35: 1205-1208)

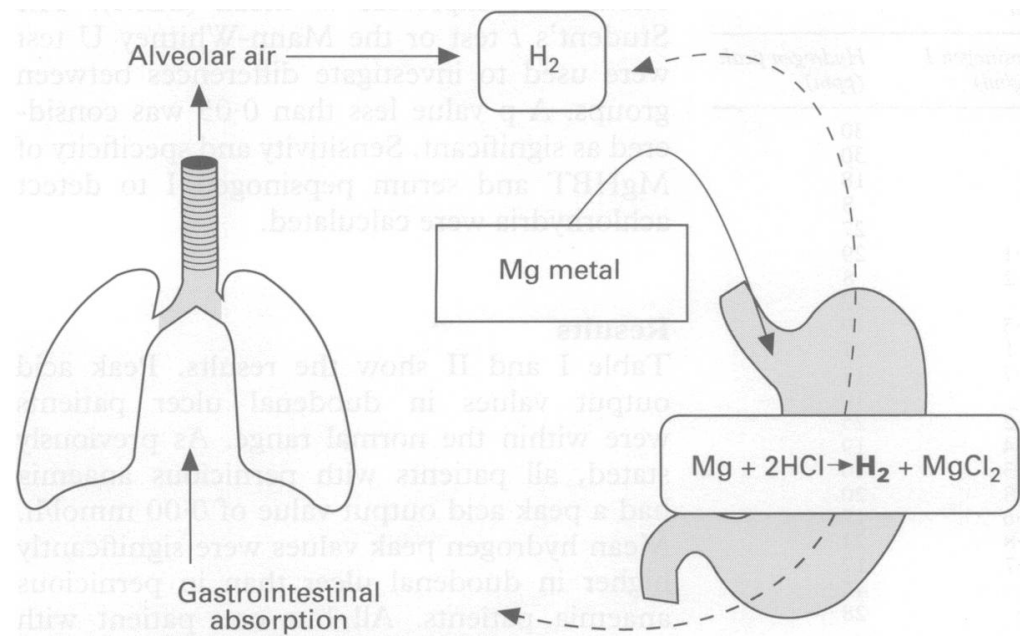

Figure 1: Schematic basis of the MgHBT.
Pentagastrin resistant achlorhydria is a characteristic feature of pernicious anaemia. Its absence rules out this diagnosis. To avoid gastric intubation and the drawbacks of traditional gastric secretion tests, some alternative non-invasive methods, such as technetium$99 \mathrm{~m}$ ( $99 \mathrm{~m} \mathrm{Tc})$ gastric scintigraphy ${ }^{1}$ or the measurement of serum pepsinogen I concentrations, ${ }^{2}$ have been proposed.

As pepsin and acid secretion both decline to the point of virtual or complete absence in atrophic gastritis, the measurement of serum pepsinogen I had been considered to be an indirect method to diagnose achlorhydria in patients with pernicious anaemia. ${ }^{3}$ $\mathrm{Carmel}^{4}$ showed the low serum pepsinogen I concentrations $(<30 \mu \mathrm{g} / \mathrm{l})$ occurred in $92 \%$ of patients with pernicious anaemia. The author concluded that serum pepsinogen I measurement is the most sensitive serum marker for pernicious anaemia. Pepsinogen I assay, however, is expensive, requires sophisticated equipment, and qualified personnel.

In 1985, Sack et $a l^{5}$ developed a noninvasive tubeless method to measure gastric acid secretion. It was based upon the reaction of ingested magnesium metal with gastric acid to produce hydrogen (Fig 1), which was detected in the exhaled air and belches by gas chromatography. The technique required the collection of the total air exhaled into a 120 litre balloon, the measurement of the air volume, and the calculation of the water vapour content in each sample. Therefore, this approach was difficult to use in clinical practice.

In our study, the magnesium hydrogen breath test (mgHBT) has been modified using end expiratory breath sampling, to make it suitable for clinical use. In addition, the accuracy of both MgHBT and serum pepsinogen I for assessing achlorhydria in the diagnostic investigation of pernicious anaemia have been compared.

\section{Subjects and methods}

SUBJECTS

Twenty one patients with pernicious anaemia ( 8 male, 13 female; 612.8 years mean (SEM)), and 22 endoscopically proved healed duodenal ulcer patients with normalchlorhydria (19 male, 3 female; 46.1 (2) years) were included in the study. The diagnosis of pernicious anaemia was based upon the finding of low serum cobalamin concentration, positive Schilling 


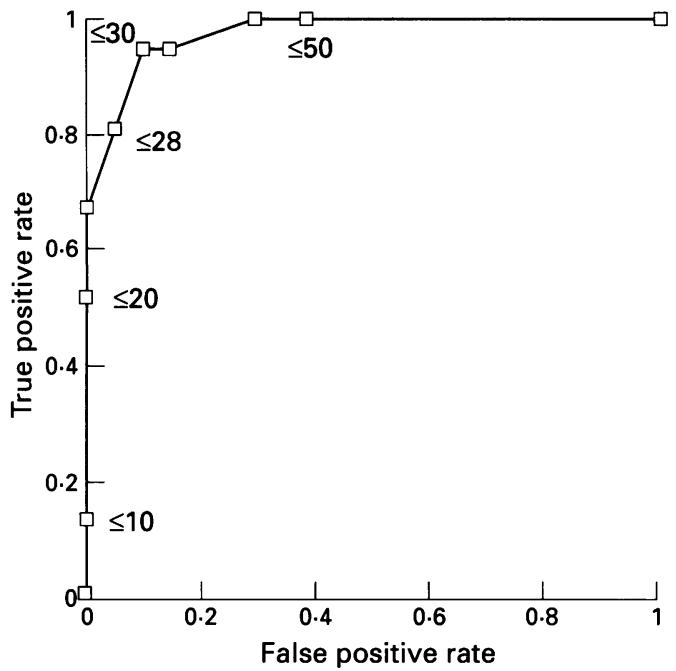

Figure 2: ROC curve of hydrogen peak concentration.

test, histologically proved fundal atrophic gastritis, and pentagastric resistant achlorhydria. ${ }^{6}$ All subjects gave informed consent and the study protocol was approved by the research committee of the hospital and performed in accordance with the Helsinki Declaration.

\section{PROCEDURES}

In duodenal ulcer patients all antisecretory drugs had been withdrawn one week before each test. All subjects fasted overnight and refrained from smoking.

Fasting serum samples for pepsinogen I and gastric assays were obtained before the $\mathrm{MgHBT}$ and stored at $-30^{\circ} \mathrm{C}$. Pepsinogen I and gastrin concentrations were determined by a competitive binding double antibody radioimmunoassay (Pepsik, Sorin Biomedica, Italy; and Gastrin, Diagnostic Products Corporation. USA). ${ }^{78} \mathrm{~A}$ pepsinogen I concentration lower than $30 \mu \mathrm{g} / \mathrm{l}$ was considered suggestive of pernicious anaemia. ${ }^{4}$ Standard gastric acid secretory tests were carried out in all patients. Basal acid output, and peak acid output after injecting $6 \mu \mathrm{g} / \mathrm{kg}$ pentagastrin IM

TABLE I Individual values of pepsinogen I and hydrogen peak in both groups of patients

\begin{tabular}{|c|c|c|c|c|c|}
\hline \multicolumn{3}{|c|}{ Duodenal ulcer } & \multicolumn{3}{|c|}{ Pernicious anemia } \\
\hline Case no & $\begin{array}{l}\text { Pepsinogen I } \\
(\mathrm{ng} / \mathrm{ml})\end{array}$ & $\begin{array}{l}\text { Hydrogen peak } \\
\text { (ppm) }\end{array}$ & Case no & $\begin{array}{l}\text { Pepsinogen } I \\
(\mathrm{ng} / \mathrm{ml})\end{array}$ & $\begin{array}{l}\text { Hydrogen peak } \\
\text { (ppm) }\end{array}$ \\
\hline 1 & $63 \cdot 4$ & 52 & 1 & 13 & 30 \\
\hline 2 & $97 \cdot 3$ & 90 & 2 & 0 & 30 \\
\hline 3 & 148.0 & 45 & 3 & 5 & 18 \\
\hline 4 & $62 \cdot 3$ & 87 & 4 & 18 & 8 \\
\hline 5 & 86.9 & 72 & 5 & 0 & 27 \\
\hline 6 & 135.0 & 100 & 6 & $10 \cdot 1$ & 29 \\
\hline 7 & 134.0 & 85 & 7 & $4 \cdot 2$ & 8 \\
\hline 8 & $110 \cdot 0$ & 48 & 8 & 16 & 22 \\
\hline 9 & $57 \cdot 2$ & 52 & 9 & $12 \cdot 5$ & 19 \\
\hline 10 & $226 \cdot 0$ & 86 & 10 & $0 \cdot 1$ & 27 \\
\hline 11 & $212 \cdot 0$ & 109 & 11 & $16 \cdot 7$ & 17 \\
\hline 12 & $79 \cdot 3$ & 59 & 12 & 5 & 10 \\
\hline 13 & $247 \cdot 0$ & 72 & 13 & $5 \cdot 2$ & 25 \\
\hline 14 & $31 \cdot 7$ & 140 & 14 & $10 \cdot \overline{4}$ & 19 \\
\hline 15 & $171 \cdot 0$ & 68 & 15 & $10 \cdot 3$ & 16 \\
\hline 16 & $120 \cdot 0$ & 53 & 16 & $5 \cdot 8$ & 20 \\
\hline 17 & 136.0 & 47 & 17 & $11 \cdot 6$ & 17 \\
\hline 18 & $79 \cdot 4$ & 43 & 18 & $4 \cdot 8$ & 24 \\
\hline 19 & $128 \cdot 0$ & 61 & 19 & $8 \cdot 7$ & 17 \\
\hline 20 & 125.0 & 54 & 20 & 7 & 45 \\
\hline 21 & 118.0 & 65 & 21 & 27 & 28 \\
\hline 22 & 150.0 & 80 & & & \\
\hline
\end{tabular}

(Peptavlon, ICI-Farma SA, Spain), were measured. Normal chlorhydria was defined as a peak acid output between $8 \cdot 0$ and $60.6 \mathrm{mmol} / \mathrm{h}$.

MgHBT was carried out one week after the gastric acid analysis. The day before the breath test, all subjects ate a non-absorbable carbohydrate free diet. ${ }^{9}$ After a 12 hour overnight fast, three end expiratory breath samples ${ }^{10}$ were obtained (baseline). Thirty minutes after $6 \mu \mathrm{g} / \mathrm{kg}$ pentagastrin IM was given, subjects swallowed $150 \mathrm{mg}$ of magnesium metal (0.1-0.3 mm, Art 5815, Merck-Igoda, Spain) suspended in $10 \mathrm{ml}$ of water, followed immediately by $100 \mathrm{ml}$ of tap water. In contrast with Sack's method, ${ }^{5}$ glucose syrup was not used to suspend magnesium metal because it induces breath hydrogen excretion in achlorhydric patients (unpublished findings), probably because of gastric bacterial overgrowth.

Twenty $\mathrm{ml}$ end expiratory breath samples were obtained at five minute intervals during the first hour, and at 10 minute intervals during the second hour. Belches were collected if they occurred in a $300 \mathrm{ml}$ bag with an unidirectional valve. In such cases, $20 \mathrm{ml}$ samples were obtained from the bag to determine the hydrogen concentration in each belch. Patients were seated but awake and refrained from smoking during the whole test period. ${ }^{11}$ Samples were immediately analysed and the hydrogen concentration measured by means of hydrogen sensitive conductance using a Lactoscreen hydrogen analyser (range 0-200 ppm, accuracy $\pm 2 \%$, Grifols SA, Barcelona, under licence of Hoek Loos, The Netherlands). This method has previously been shown to have an excellent correlation with gas chromatography. ${ }^{12} \mathrm{~A}$ hydrogen peak value above basal excretion $\leqslant 30 \mathrm{ppm}$ was considered indicative of achlorhydria. A receiver operating characteristic (ROC) curve was used to define this cut off value (Fig 2).

In four additional patients with duodenal ulcers, MgHBT was repeated after 48 hours of omeprazole treatment ( $40 \mathrm{mg} /$ day) to assess the efficacy of the test to evaluate drug induced achlorhydria.

\section{STATISTICS}

Results are expressed as mean (SEM). The Student's $t$ test or the Mann-Whitney U test were used to investigate differences between groups. A p value less than 0.05 was considered as significant. Sensitivity and specificity of MgHBT and serum pepsinogen I to detect achlorhydria were calculated.

\section{Results}

Table I and II show the results. Peak acid output values in duodenal ulcer patients were within the normal range. As previously stated, all patients with pernicious anaemia had a peak acid output value of $0.00 \mathrm{mmol} / \mathrm{h}$. Mean hydrogen peak values were significantly higher in duodenal ulcer than in pernicious anaemia patients. All but one patient with pernicious anaemia and none with duodenal 
TABLE II Results of acid secretion studies in both groups of patients (mean (SEM))

\begin{tabular}{lccc}
\hline & Pernicious anaemia & Duodenal ulcer & $p$ Value \\
\hline Pepsinogen I $(\mu \mathrm{g} / \mathrm{l})$ & $10 \cdot 7(2 \cdot 7)$ & $123 \cdot 6(11 \cdot 8)$ & $0 \cdot 00005$ \\
Gastrin $(\mathrm{pg} / \mathrm{ml})$ & $777 \cdot 1(92 \cdot 1)$ & $66 \cdot 2(11 \cdot 4)$ & $0 \cdot 00005$ \\
Peak acid output $(\mathrm{mmol} / \mathrm{h})$ & 0 & $43(4 \cdot 8)$ & $0 \cdot 00005$ \\
Hydrogen peak $(\mathrm{ppm})$ & $21 \cdot 7(1 \cdot 9)$ & $71 \cdot 3(5 \cdot 2)$ & 0.00005 \\
\hline
\end{tabular}

ulcer had hydrogen peak values $\leqslant 30 \mathrm{ppm}$ (Fig 3).

Patients with pernicious anaemia had no belches during the test, whereas they occurred in two subjects in the duodenal ulcer group. No side effects attributable to magnesium were seen.

As expected, serum pepsinogen I concentrations were significantly lower in pernicious anaemia than in the duodenal ulcer group (Table II). Serum gastrin concentrations were increased in most cases with pernicious anaemia (above $100 \mathrm{ng} / 1$ in $86 \%$ of the patients). All pernicious anaemia patients and none with duodenal ulcer had serum concentrations of pepsinogen I lower than $30 \mu \mathrm{g} / \mathrm{l}$ (Fig 3).

Sensitivity and specificity to detect achylorydria in pernicious anaemia were $95.24 \%$ and $100 \%$ for MgHBT, whereas they were both $100 \%$ for serum pepsinogen I.

Hydrogen peak values decreased considerably in three of four duodenal ulcer patients after 48 hours of $40 \mathrm{mg}$ omeprazzole treatment (Fig 4).

\section{Discussion}

Various direct and indirect tests are used to diagnose pernicious anaemia in patients with megaloblastic anaemia and vitamin B-12 deficiency. These include the Schilling test, intrinsic factor assay in gastric juice, assay for anti-parietal cell and anti-intrinsic factor antibodies, and gastric acid secretion analysis. Some are expensive because they need radioisotopes and special equipment, whereas others are simple but uncomfortable for the patients and have some drawbacks. ${ }^{61314}$ The presence of achlorhydria, however, together with other elements of the clinical picture, is considered sufficient for establishing the diagnosis of pernicious anaemia. ${ }^{6}$ Accordingly, non-invasive tests to study gastric acid secretion have been proposed. ${ }^{12}$
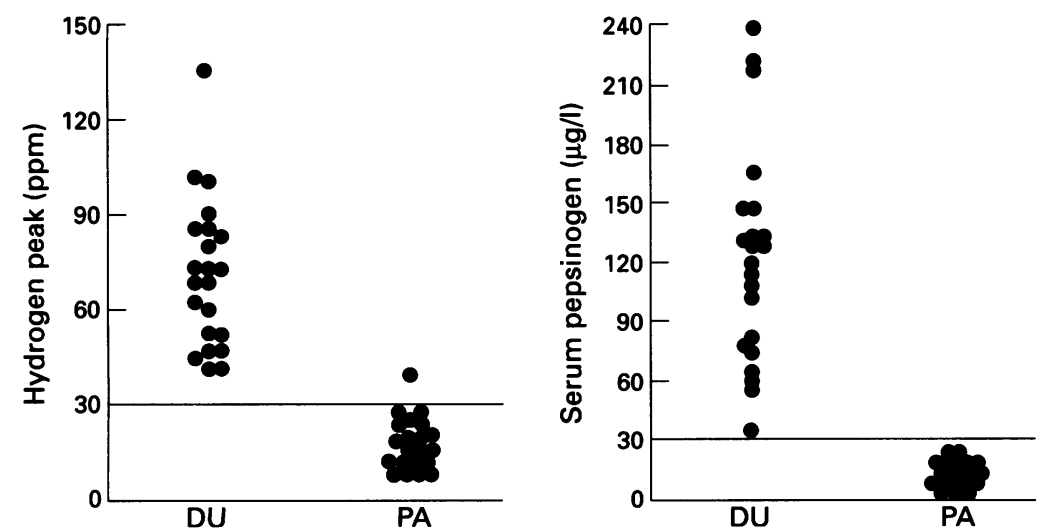

Figure 3: $(A)$ Hydrogen peak (ppm) and (B) serum pepsinogen $I(\mu g /)$ concentrations of patients with pernicious anaemia (PA) and duoedenal ulcer (DU). Points below the horizontal line represent achlorhydria.

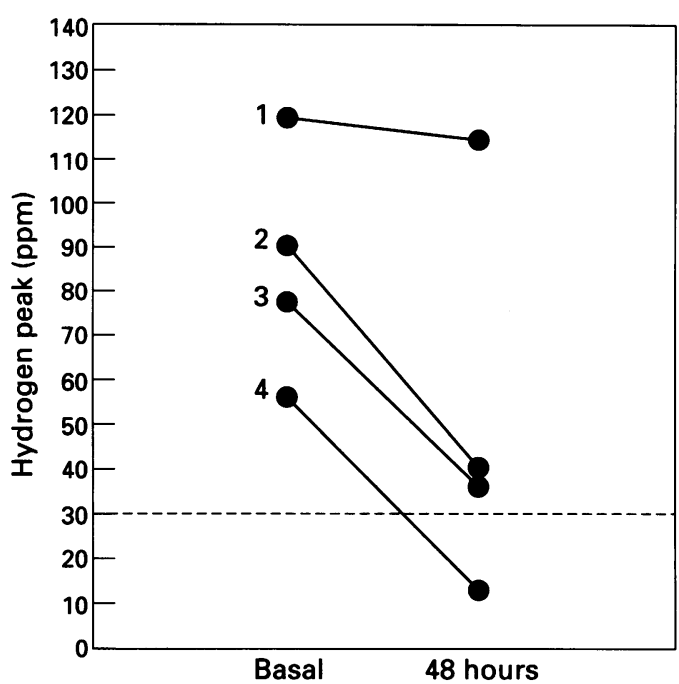

Figure 4: Evolution of hydrogen peak in duodenal ulcer patients after 48 hours of $40 \mathrm{mg}$ omeprazole treatment. Dotted line represents achlorhydria level.

The measurement of serum pepsinogen I has been shown to be a non-invasive and sensitive method to detect pernicious anaemia. ${ }^{4}$ In this series, the frequency of low concentrations of serum pepsinogen $I$ in patients with pernicious anaemia was similar to that previously published. ${ }^{4}$ The analysis of serum pepsinogen I, however, also requires specific equipment for radioimmunoassay, not available in all centres. Another disadvantage of the pepsinogen I assay is the delay in obtaining the results as, to reduce costs, the samples cannot be analysed until enough serum samples are collected to complete an assay kit.

The modifications of the MgHBT described in this paper, mainly end expiratory sample collections, make the test simpler and more suitable for clinical use than the original Sack's technique. The equipment for measuring breath hydrogen by hydrogen sensitive conductance is not expensive and requires little technical support. It is easy to use and can be used by non-qualified personnel. On the other hand, in the light of the results, the study of spontaneous belches does not seem to be necessary in patients with either achlorhydria or normal chlorhydria. In these cases, the measurement of end expiratory breath samples is enough to detect the absence or presence of acid in the stomach.

The cut off value of $\leqslant 30 \mathrm{ppm}$ over the basal hydrogen excretion was the maximum discrimination point in the ROC curve. The increase in hydrogen excretion until $30 \mathrm{ppm}$ in patients with pernicious anaemia may have, at least, one possible explanation. An early increase in hydrogen concentration has been described during a hydrogen breath test because, in part, of a reflex emptying to the caecum of carbohydrate residues in the ileum from a previous meal, a manifestation of the so called 'gastroileal reflex'. ${ }^{15}$ It was shown, however, that the magnitude of these hydrogen concentration increments was unlikely to be greater than $20 \mathrm{ppm}$, ranged from 4 to $31 \mathrm{ppm}$ (median $8 \mathrm{ppm}$ ), and wore off within 60 minutes in $80 \%$ of the cases. ${ }^{16}$

In this study, hydrogen peak values had a 
high sensitivity and specificity, similar to that of serum pepsinogen I concentrations, to detect achlorhydria in patients with pernicious anaemia. In addition to its practicability, the MgHBT offers the advantage that the results are immediately available. For this reason, the MgHBT could be included in the diagnostic investigation of the patients with low serum concentrations of cobalamin, macrocytosis or unexplained neurological disturbances before performing other more uncomfortable tests such as fibregastroscopy or the classic gastric acid secretion study. On the other hand, the finding of a low hydrogen peak concentration in patients with non-conclusive low range serum cobalamin concentrations (between $100-200 \mathrm{pg} / \mathrm{ml}$ ) could suggest the existence of pernicious anaemia in an early stage. Furthermore, the MgHBT might also be included in the diagnostic investigation of anaemias of unexplained origin.

As achlorhydria may precede by many years fully developed pernicious anaemia, ${ }^{6}$ the MgHBT may be useful as a screening tool in relatives of patients with pernicious anaemia.

An additional use of the MgHBT might be the assessment of the response to antisecretory treatment in acid related diseases. In this sense, we have also shown that the 48 hour response to $40 \mathrm{mg}$ oral omeprazole administration was adequate in only three of four duodenal ulcer patients treated. The value of the MgHBT after omeprazole treatment, however, needs further study.

It is concluded that the modified MgHBT using end expiratory sampling is a simple, non-invasive, cost effective, and accurate method to assess achlorhydria and may be useful in the diagnostic investigation of patients with suspected pernicious anaemia and for screening of their relatives.

We thank Dr Pilar Giner from the department of pharmacy and Mrs Pepi Vega for kindly cooperating in this study.

1 Taylor TV, Holt S, McLoughlin GP, Heading RC. A single scan technique for estimating acid output. Gastroenterology 1979; 77: 1241-4.

2 Samloff IM, Secrist MD, Passaro E. A study of the relationship between serum group I pepsinogen levels and gastric acid secretion. Gastroenterology 1975; 69: 1196-200.

3 Hirschowitz BI. Pepsinogen. Postgrad Med 7 1984; 60: 743-50.

4 Carmel R. Pepsinogens and other serum markers in pernicious anaemia. Am $\mathcal{F}$ Clin Pathol 1988; 90: 442-5.

5 Sack DA, Stephenson CB. Liberation of hydrogen from gastric acid following administration of oral magnesium. Dig Dis Sci 1985; 12: 1127-33.

6 Babior BM. The megaloblastic anemias. In: Williams WJ, Beutler E, Erslev AJ, Lichtman MA, eds. Hematology, New York: McGraw-Hill, 1990: 453-81.

7 Samloff IM. Pepsinogens I and II: purification from gastric mucosa and radioimmunoassay in serum. Gastroenterology 1982; 82: 26-33.

8 Lindstedt G. Analytical and clinical evaluation of a radioimmunoassay for gastrin. Clin Chem 1985; 31: 76-82.

9 Kotler DP, Holt PR, Rosenweig NS. Modification of the hydrogen breath test: increased sensitivity for the detection of carbohydrate malabsorption. $\mathcal{F}$ Lab Clin Med 1982; 100: 798-805.

10 Metz G, Gassull MA, Leeds AR, Blendis LM, Jenkins DJA A simple method of measuring breath hydrogen in carbohydrate malabsorption by end-expiratory sampling. Clin hydrate malabsorption by end-
Sci Mol Med 1976; 50: $237-40$.

11 Thompson DG, Binfield P, de Belder A, O'Brien J, Warren $S$, Wilson $M$. Extra intestinal influences on exhaled breath hydrogen measurements during the investigation of gastrointestinal disease. Gut 1985; 26: 1349-52.

2 Van der Klei-Van Moorsel JM, Douwes AC, Van Oeveren JP. New principle for estimation of hydrogen in expired air. Eur $\mathcal{F}$ Pediatr 1984; 141: 221-4.

13 Jacobson BE, Onstad GR. Misleading second-stage Schilling tests due to inactive intrinsic factor concentrate. Ann Intern Med 1979; 91: 579-80.

14 Feldman M. Gastric acid secretion in health and disease. In: Sleisenger MH, Fordtran JS, eds. Gastrointestinal disease. Sleisenger MH, Fordtran JS, eds. Gastroin

15 Read NW, Al-Janabi MN, Bates TE, Holgate AM, Cann $\mathrm{PA}$, Kinsman RI, et al. Interpretation of the breath hydrohen profile obtained after ingesting a solid meal containing unabsorbable carbohydrate. Gut 1985; 26: 834-42.

16 Rumessen JJ, Kokholm G, Gudmand-Hoyer E. Methodological aspects of breath hydrogen (H2) analysis. Evaluation of a $\mathrm{H} 2$ monitor and interpretation of the breath test. Scand f Clin Lab Invest 1987; 47: 555-60. 